\title{
A Comparative Study of the Effectiveness of Serum C-reactive Protein and Serum Pentraxin-3 Levels in the Diagnosis and Follow-up of Neonatal Sepsis
}

\author{
๑ Tugrul Atay, ๑ Kamil Sahin, ๑ Murat Elevli, ๑ Ala Ustyol, ๑ Demet Oguz, ๑ Emel Ataoglu, \\ - Hatice Nilgun Duru \\ University of Health Sciences Turkey, Istanbul Haseki Training and Research Hospital, Clinic of Pediatrics, Istanbul, Turkey
}

Abstract

\begin{abstract}
Aim: Neonatal sepsis is a disease with multisystemic involvement accompanied by bacteremia in the first 28 days of life and in which the pathogen micro-organism spreads to different systems via the blood. Laboratory tests with high sensitivity and specificity are needed for the early diagnosis of neonatal sepsis. The purpose of this study was to investigate the effectiveness of pentraxin 3 in neonatal sepsis.

Methods: This prospective clinical study was performed between November, 2015, and March, 2016, with 49 newborns diagnosed with sepsis and under monitoring at the neonatal intensive care unit and with Tollner sepsis scores of 5 or above and with 35 healthy neonates. Blood was collected from every patient diagnosed with sepsis for complete blood count, C-reactive protein, blood culture and pentraxin 3 measurements.
\end{abstract}

Results: No significant difference was determined between the patient and control groups in terms of birth weight or gender. C-reactive protein, leukocyte, and pentraxin 3 levels were found to differ significantly between the healthy newborns in the control group and the septic patients. A significant correlation was observed between pentraxin 3 levels and serum C-reactive protein levels $(r=0.44, p<0.05)$. The area under the curve was statistically significant at logistic regression analysis (area: 0.782).

Conclusions: The data from our study show that pentraxin 3 may represent a valuable marker in the differential diagnosis of neonatal sepsis.

Keywords: C-reactive protein, newborn, pentraxin, sepsis

*This manuscript have presented as oral presentation in “5. Çocuk Dostları Kongresi İstanbul-Türkiye,” on 6-8 March 2017.

\section{Introduction}

Although sepsis in neonates is increasingly less prevalent in developed countries, it continues to represent a cause of significant mortality and morbidity (1). Neonatal sepsis is seen in 1-10/1000 live births. Despite the advances made in antibiotherapy in neonatal sepsis, there are still vital problems for both term and premature newborns (2). Neonatal sepsis is classified as early-onset sepsis (ENS) (0-3 days) or late-onset sepsis (LNS) (4-28 days), depending on the time of onset of symptoms and findings, and as unproved (presence of bacterial growth in hemoculture) or clinical sepsis (no bacterial growth in hemoculture), depending on whether or not a microbiological agent is isolated (3).

The gold standard in the diagnosis of sepsis is the growth of one or more microbial agents in blood culture. However, this is not always possible. The main assistant techniques in diagnosis involve inflammatory markers such as white cell count and C-reactive protein (CRP), procalcitonin, fibrinogen, ceruloplasmin, haptoglobin, interleukin-6 (IL-6), serum amyloid-A (SAA), and pentraxin-3 (PTX-3) (4). PTX-3 is an endothelium and 
macrophage-derived inflammatory marker and has been used as such in several studies, particularly in cardiovascular diseases (5).

The purpose of this study was to investigate the role of PTX-3 in the diagnosis and treatment of neonatal sepsis.

\section{Methods}

Approval for the study was also granted by the University of Health Sciences Turkey, Istanbul Haseki Training and Research Hospital Ethical Committee (approval number: 271/2015, date: 16.12.2015). Written consent to participate was obtained from the parents of all the babies enrolled before the study commenced.

This study was performed between October, 2015, and April, 2016, with 49 neonatal patients being monitored and treated with a preliminary diagnosis of sepsis in our hospital neonatal intensive care unit and with 35 healthy newborn babies born without complications. The sepsis group and the control group were weighed using a SEGA digital. Babies born before 37 gestational weeks were regarded as preterm. Those born after 40 weeks were regarded as post-term. Babies weighing less than $2500 \mathrm{~g}$ were regarded as low birth weight, and neonates with a rectal temperature above $38{ }^{\circ} \mathrm{C}$ were regarded as febrile.

In addition to risk factors such as urogenital infection in the mother, peripartum fever, presence of early membrane rupture, home birth, early birth and low birth weight, diagnosis of neonatal sepsis was made by excluding other diseases that might cause these conditions in newborns with findings such as reducing sucking in the newborn, reduced or low newborn reflexes, cyanosis, retraction, grunting, respiration, tachypnea, tachycardia, hypothermia, hyperthermia, vomiting, diarrhea, lethargy, hypotonia, irritability, jaundice, bulging fontanelle, cutis mormarata, and cutaneous eruptions.

All patients treated with a diagnosis of neonatal sepsis were scored according to the Tollner system, and patients scoring between 5 and 15 were included in the study. Under this method, which permits a clinical approach to cases of suspected sepsis, a score below shows an absence of sepsis (negative), scores of 5-10 indicate suspected sepsis, and scores above 10 show the presence of sepsis (6) (Table 1).

Blood samples were collected from the patient group before the start of antibiotic therapy for blood count, blood culture, CRP and PTX-3 study. One-milliliter venous blood specimens were placed in a pediatric BACTEC broth medium and stored for 7 days in a hemoculture device (Becton Dickinson, Phoenix 100). During this time, those exhibiting growths were gram stained and identification was performed.
Cord bloods were placed into gel separator tubes without additives immediately after birth. Blood specimens from patients with early and late sepsis were placed into gel separator tubes without additives once the diagnosis had been made and were centrifuged for 10 min at 1500 g. Venous specimens for complete blood count were placed into EDTA tubes. CRP and complete blood count were investigated on the same day. Specimens for PTX-3 were set aside and immediately placed in a deep freeze at $-80^{\circ} \mathrm{C}$ until assay.

CRP was investigated using the immunoturbidimetric method on a Beckman Coulter AU2700 biochemistry autoanalyzer (Beckman, California, USA). Complete blood count parameters were studied on a Mindray BC-3000 (Mindray, Shenzhen, China) hematology analyzer. PTX-3 values were studied manually with the help of a Biotek ELX800 (Biotek, Winooski, VT, USA) ELISA reader. PTX-3 was investigated with a Bioassay commercial ELISA kit (Stegmann Systems GmbH, Germany).

\section{Statistical Analysis}

Statistical analyses were performed on SPSS Version 20.0 (For Windows, SPSS Inc., Chicago, IL, USA) software. Descriptive statistics were expressed as number and percentage for categorical variables and mean, standard deviation and minimum and maximum values for numerical variables. The normality of data was analyzed using the Kolmogorov-Smirnov test. Intergroup comparisons were performed using Student's t-test when numerical variables were normally distributed and using the Mann-Whitney $U$ test when not normally distributed. Comparisons between more than two groups were performed using ANOVA in case of normal distribution and with the Kruskal-Wallis test when normal distribution was not established. Differences between categorical variables were assessed using the chisquare test. Correlations between variables were evaluated using the Spearman test. Receiver operating characteristic analysis was performed to determine the highest PTX3 value with the highest sensitivity and specificity in predicting sepsis. Alpha significance was accepted $<0.05$.

\section{Results}

The patient newborns' chronological ages ranged between 0 and 28 days, gestational weeks between 35 and 39, and birth weights between $2400 \mathrm{~g}$ and $3900 \mathrm{~g}$. Control group birth weights were $2300-4550 \mathrm{~g}$ and their birth weeks ranged between 36 and 39. There was no statistically significant difference between the groups in terms of gestational weeks or weight distributions (Table 2). No significant difference was observed between the early and late-sepsis groups and control groups.

Significant differences were observed in leukocyte, PTX-3 and CRP values between the study and control groups $(p<0.05)$. No significant difference was observed in platelet values (Table 3, Figure 1). 


\begin{tabular}{|l|l|l|l|l|}
\hline Table 1. Tollner scoring & $\mathbf{0}$ & $\mathbf{1}$ & $\mathbf{2}$ & $\mathbf{3}$ \\
\hline Score & None & & Moderate & Marked \\
\hline Change in skin color & None & & Impaired & Marked \\
\hline Peripheral circulation impairment & None & Moderate & Marked & \\
\hline Hypotonia & None & Present & & \\
\hline Bradycardia & None & Present & & \\
\hline Apnea & None & Present & & \\
\hline Respiratory distress & None & $>4 \mathrm{~cm}$ & & Leukopenia \\
\hline Hepatomegaly & None & Present & & Marked \\
\hline Gastrointestinal finding & Normal & Leukocytosis & & Moderate \\
\hline Leukocyte count & None & & Present & \\
\hline Band/segmented neutrophil & None & & $<7.2$ & \\
\hline Thrombocytopenia & None & $\mathbf{7 . 2}$ & \\
\hline Metabolic acidosis $(\mathbf{p H})$ & &
\end{tabular}

Examination of the study group revealed a significant correlation between serum PTX-3 and serum CRP levels and Tollner sepsis scores $(p=0.001$ and $p<0.05$, respectively) (Table 4).

No statistically significant difference was determined in the PTX-3 and CRP values, leucocyte and platelet count between the early and late-neonatal sepsis groups. No statistically significant difference was determined in the parameters (PTX-3, CRP, leucocyte, and platelet) investigated in the sepsis patient group in terms of gender.

At a cut-off value of $3.26 \mathrm{ng} / \mathrm{ml}$ for PTX-3, sensitivity

Table 2. Comparison of the study groups' gestational week and birth weight

\begin{tabular}{|l|l|l|l|}
\hline & Sepsis group & Control group & \multirow{2}{*}{$\mathbf{P}^{1}$} \\
\cline { 2 - 4 } & Mean \pm SD & Mean \pm SD & \\
\hline Week & $34.45 \pm 4.26$ & $35.32 \pm 2.69$ & 0.564 \\
\hline Weight (gram) & $3211.2 \pm 425.7$ & $3342.2 \pm 558.7$ & 0.226 \\
\hline $\begin{array}{l}\text { 'Mann-Whitney U test. } \\
\text { There was no statistically significant difference between the groups in terms of } \\
\text { gestational weeks or weight } \\
\text { SD: Standard deviation }\end{array}$ \\
\hline
\end{tabular}

was $81 \%$ and specificity $69 \%$, while positive predictive value was $78.4 \%$ and negative predictive value (NPV) 72.7\% (Table 5) (Figure 2).

\section{Discussion}

Difficulties may sometimes be experienced in the diagnosis of neonatal sepsis, for reasons such as subtle clinical findings, late emergence of results for growth in cultures such as blood, urine and cerebrospinal fluid and the absence of a rapid specific and sensitive inflammatory biomarker for neonatal sepsis (7).

Gürsu et al. (8) reported that sepsis in the neonatal period was twice as common in males as in females. The male-female ratio in the patient group in our study was 0.96 , compared to 1.18 in newborns in the control group. In Katar and Devecioğlu (9) study, male and female incidence levels in cases of sepsis were approximately equal.

No significant difference was determined between gestational weeks in the newborns In the study group (3539 weeks) and those in the control group (36-39 weeks) (Table 2). Various studies have shown that gestational weeks affect CRP levels. Only limited information is

Table 3. Comparison of laboratory values between the groups

\begin{tabular}{|l|l|l|l|}
\hline & Sepsis group & Control group & $\mathbf{P}^{1}$ \\
\hline Leukocyte & $25,901 \pm 4923.9$ & $17.872 .2 \pm 6941.1$ & $<0.05$ \\
\hline Platelet & $238,020.4 \pm 103,616.9$ & $269,257.14 \pm 85,692.7$ & 0.148 \\
\hline Pentraxin-3 & $8.1(2.04-37.2) 14.07 \pm 11.4$ & $1.79(0.75-49.8) 7.8 \pm 12.7$ & $<0.05$ \\
\hline C-reactive protein & $31.7 \pm 19.8$ & $1.42 \pm 1.6$ & $<0.05$
\end{tabular}

'Mann-Whitney $U$ test.

Significant differences were observed in leukocyte, PTX-3 and CRP values between the study and control groups

PTX-3: Pentraxin-3, CRP: C-reactive protein 


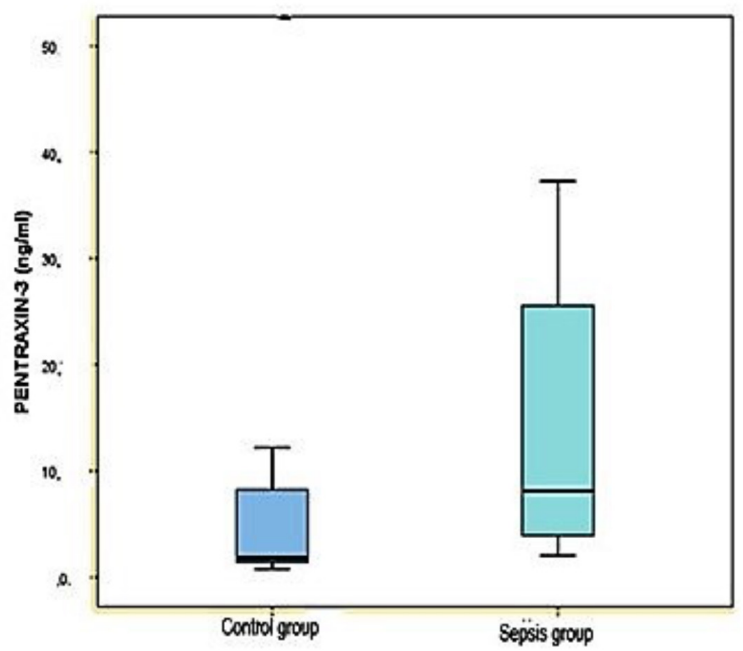

Figure 1. Patient and control group serum pentraxin-3 levels

available in the literature concerning how PTX-3 changes with age in the neonatal period. PTX-3 levels, the main subject of investigation in our study, varied depending on gestational weeks. In a study from Turkey, Akin et al. (10) reported that PTX-3 levels rose as gestational week decreased. Due to the low numbers in our study group and the fact that gestational weeks were close to one another, we were unable to analyze how PTX-3 changes with age on the basis of our own data. No significant relation was determined between sex and PTX-3 levels ( $p>0.05)$. No significant difference was determined between the birth weights of patients diagnosed with and treated for sepsis (2400 and $3900 \mathrm{~g}$ ) and those of the babies in the control group (2300 and $4550 \mathrm{~g}$ ) (Table 2).

Blood culture growth rates in the identification of neonatal sepsis and the pathogen micro-organism involved range between $6 \%$ and $82 \%$. This rate did not exceed $80 \%$ even in newborns with very severe sepsis (11). In our study, growth in culture was determined in eight $(16 \%)$ of the 49 patients under monitoring for sepsis in our study. We think that the low growth rates in culture

Table 4. Analysis of correlation between Pentraxin-3 and C-reactive protein, leukocyte count and Tollner sepsis scores

\begin{tabular}{|l|l|l|}
\hline & $\mathbf{R}$ & $\mathbf{p}$ \\
\hline C-reactive protein & 0.44 & 0.001 \\
\hline Tollner & 0.62 & $<0.05$ \\
\hline Leukocyte & -0.42 & 0.774 \\
\hline Platelet & -0.144 & 0.324 \\
\hline Spean & &
\end{tabular}

Spearman correlation analysis, Examination of the study group revealed significant correlation between serum PTX-3 and serum CRP levels and Tollner sepsis scores.

PTX-3: Pentraxin-3, CRP: C-reactive protein

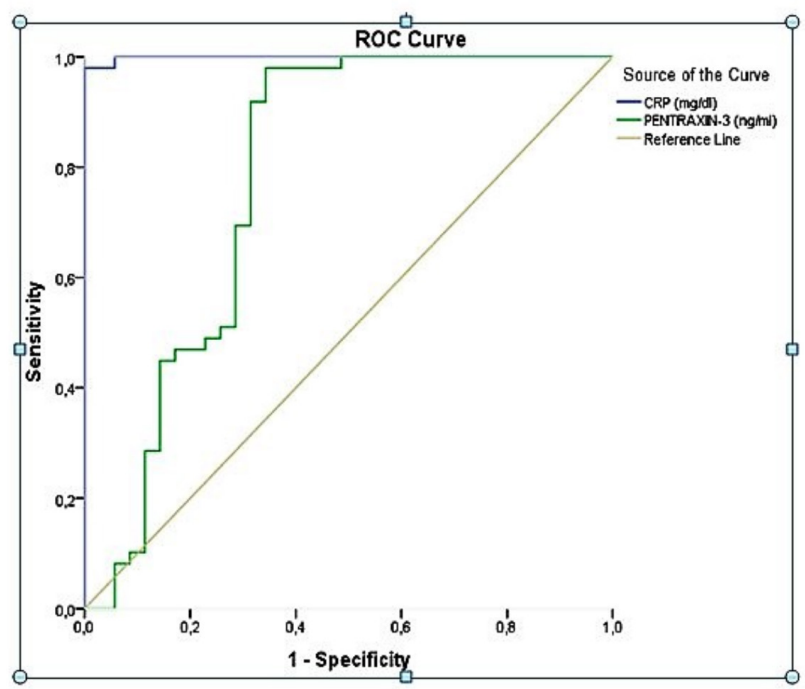

Figure 2. ROC curve analysis of Pentraxin-3 and CRP values ROC: Receiver operating characteristic, CRP: C-reactive protein

may have been caused by factors such as technical errors during specimen collection and addition to culture, the small amount of material collected for blood culture and antibiotics being given before culture was taken. Different results have been reported in publications from Turkey concerning growth in blood culture. Growth rates of $66.75 \%$ were reported by Bulut et al. (12) and of 50-80\% by Satar et al. (13).

The bacteria responsible for neonatal sepsis vary from country to country Staphylococcus aureus and Escherichia coli are most commonly isolated, while group B streptococci (GBS) are less frequently identified, in developing countries. Gram-negative bacteria have been isolated twice as frequently as gram-positive bacteria (14). GBS is more common in ENS in developing countries, followed by gram-negative bacilli and staphylococci. Klebsiella pneumonia was the most commonly isolated pathogen micro-organism in early-sepsis in our study, in three of the eight cases. In Perk's (15) study from 2010, Klebsiella spp. were most commonly isolated in ENS, followed by S. epidermidis, and by GBS in third place.

No difference was determined between the sepsis patient group with growth and the sepsis patient group without growth in terms of parameters investigated

\begin{tabular}{|l|l|l|l|l|}
\hline \multicolumn{2}{|l|}{ Table 5 . ROC results for PTX-3 levels (area under the curve) } \\
\hline & & \multicolumn{3}{|l|}{$\begin{array}{l}\mathbf{9 5 \%} \text { confidence } \\
\text { interval }\end{array}$} \\
\hline Area & Standard error & $\begin{array}{l}\text { Asymptomatic } \\
\text { indicator }\end{array}$ & Lower limit & $\begin{array}{l}\text { Upper } \\
\text { limit }\end{array}$ \\
\hline 0.782 & 0.059 & $>0.05$ & 0.666 & 0.898 \\
\hline \multicolumn{5}{|l|}{ PTX-3: Pentraxin-3, ROC: Receiver operating characteristic } \\
\hline
\end{tabular}


(leukocyte count, platelet count, CRP, PTX-3, and Tollner sepsis scores). The absence of any difference between the two groups in terms of clinical (Tollner scoring) and laboratory data and the inability to determine growth in cultures of patients with a clinical diagnosis of sepsis may be attributed to a deficiency in identifying the agent micro-organism.

Leukocytosis and leukopenia may be seen at complete blood count in neonatal sepsis. This may be due to infection in the newborn, and factors such as asphyxia, stress burden during birth, various congenital diseases deriving from the baby, diseases in the mother capable of affecting the baby (preeclampsia, eclampsia and chorioamnionitis) may also be involved in changes in the leukocyte count. Differing results have been obtained concerning leukocyte count in neonatal sepsis in various studies (16). Aygün et al. (17) reported a mean leukocyte count of $16,500 \pm 10,000$. In our study, the mean leukocyte count in newborns with sepsis was $25,901 \pm 4923$, and the mean count in the control group was $17,872.29 \pm 6941.161$. We determined a significant difference between the patient and control groups $(p<0.05)$. No significant difference was determined when leukocyte counts were compared between newborns monitored and treated for sepsis with growth and newborns monitored and treated for sepsis but without growth. Platelet count is not regarded as a particularly reliable parameter for the diagnosis of neonatal sepsis (18). Thrombocytopenia may persist for approximately a week, and neonatal sepsis appears as a non-specific, late finding (19). Although thrombocytopenia is a late-emerging finding and is not a specific finding for neonatal sepsis, it may still be indicative of neonatal sepsis when evaluated together with other parameters. Platelet count is therefore included among the parameters examined under the Tollner sepsis scoring system. Berger et al. (20) determined the sensitivity of $57 \%$ and specificity of $65 \%$ for thrombocytopenia in the diagnosis of neonatal sepsis. Prevalences of thrombocytopenia between $10 \%$ and $60 \%$ have been determined in different studies (21).

Thrombocytopenia is monitored due to platelet destruction occurring by way of immune mechanisms and the pathogen micro-organism or products from the pathogen micro-organism increasing aggregation and adhesion by impairing platelets and the vascular endothelium (18). No relation has been determined in terms of the bacterium giving rise to sepsis being gramnegative or gram-positive and thrombocytopenia (12). Shyamala et al. (22) reported that gram-negative bacteria were statistically significantly more responsible for the development of thrombocytopenia than gram-positive bacteria. Seven (14.28\%) patients with thrombocytopenia were under observation in our study. No significant difference was determined between the sepsis patient group and the healthy control group in terms of platelet counts (Table 3).

CRP and SAA constitute members of the short PTX family. CRP is synthesized in the liver, particularly with the effect of IL-6. Secretion commences $4-6 \mathrm{~h}$ after the start of the inflammatory process and peak serum levels are reached after approximately 24-48 h (23). CRP's late response to the inflammatory process, serum levels peaking after 24-48 $\mathrm{h}$ and the fact that it cannot be synthesized in liver function disorders or multiorgan failures have encouraged researchers to seek a new inflammatory marker. Infection is not the sole cause of increases in CRP. Elevation in serum may also be determined due to tissue damage in conditions such as EMR, difficult birth, vacuum extraction, maternal chorioamnionitis, perinatal asphyxia and similar (23). The fact that CRP does not only rise due to infection restrict its use alone in the diagnosis of neonatal sepsis; the sensitivity of CRP in the diagnosis of neonatal sepsis ranges between $35 \%$ and $94 \%$ in different studies, and the specificity between $60 \%$ and $96 \%(20)$. The sensitivity and specificity of CRP increase in serial measurements. CRP levels below $1.0 \mathrm{mg} / \mathrm{dL}$ in two consecutive measurements increase its NPV to up to $99 \%$. Berger et al. (20) investigated CRP and leukocyte count in the diagnosis of sepsis and determined sensitivity of $75 \%$ and specificity of $86 \%$ for CRP monitored in the first three postnatal days (19). For leukopenia, the sensitivity of $67 \%$ and specificity of $90 \%$ were determined. While CRP and leukopenia in the first three days are important diagnostic parameters for ENS, CRP becomes more dominant after the first three days. Indeed, the sensitivity and specificity of CRP after the first three days increase to $86 \%$ and $87 \%$, respectively (19). Since only low levels of CRP are able to pass into the placenta, CRP in cord blood and infant blood is fetal in origin and may indicate a potential pathology (24).

A statistically significant difference was observed in our study between the septic patient group and the healthy control group in terms of serum CRP levels (Table 3). No difference was determined between serum CRP levels in babies with ENS and LNS.

PTXs are components of the natural immune system that, together with the complement system and macrophages, neutralize pathogen micro-organisms and scavenge metabolic wastes (25).

CRP release begins in 4-6 $\mathrm{h}$ after the inflammatory process, and peak serum values are reached in 2448 h, while PTX-3 levels in serum increase up to 100fold 6-h after the start of synthesis. PTX-3 is produced independently of liver functions (25). For reasons such as PTX-3 being produced independently of liver functions and 
reaching peak serum levels more quickly, the view that it will reflect infection better than traditionally used markers has emerged. Data obtained from patients in septic shock with meningococcal disease in adults and children confirm this (26).

PTX-3 has become the subject of research in numerous different areas; for example, it has been investigated in the diagnosis of cardiovascular diseases in adults in several studies. PTX-3 levels in the diagnosis and monitoring of treatment of pediatric vasculitis and adult and pediatric patients with septic shock, and its relations with prognosis, mortality and morbidity in these diseases have also been examined $(27,28)$.

Data concerning PTX-s in the neonatal period are limited. In a study from Turkey published in 2014, Akin et al. (10) measured and compared serum PTX-3 levels of neonates born to mothers with early membrane ruptures and of those mothers. No correlation was determined between maternal and baby serum PTX-3 levels in this study (24). In the light of that information, we think that PTX-3 (long pentraxin) may also be unable to cross the placenta. We also examined PTX-3 values in cord blood in 20 healthy neonates. Serum PTX-3 elevation in cord blood may indicate a probable pathology deriving from the baby. Akin et al. (10) determined an inverse correlation between a gestational week and PTX-3 levels and a direct correlation in subjects with intraventricular bleeding and mortality. High serum PTX-3 levels were determined in subjects with a low Apgar score, respiratory distress syndrome, clinical sepsis, intraventricular hemorrhage, necrotizing enterocolitis and prolonged hospitalization in the neonatal intensive care unit. Higher proportions of neurological and cardiac problems were determined in patients with PTX-3 elevation. High PTX-3 levels have been observed in newborns with hypoxicischemic diseases and low ejection fraction at simultaneous echocardiography (29). Myocardial depression initiates a response in the central nervous system in association with impairment of tissue blood supply as a result of hypo- and hypertension, and PTX-3 may start being released from neurons. Other long pentraxins, such as neuronal PTX-1 and human neuronal PTX-2 are released in the event of neuron damage and can reach high levels in the blood (30). In the study of Duman et al. (31), They found $72.97 \%$ sensitivity and $88 \%$ specificity values for PTX $9.3 \mathrm{ng} / \mathrm{mL}$ in the diagnosis of appendicitis. In coronavirus diseases-2019 (COVID-19) patients, a strong relationship was found between early death and PTX-3 values (32). PTX-3 was found to be lower in patients with COVID-19 pulmonary sepsis than in patients with other pulmonary sepsis (33).

A significant difference was determined in our study in terms of PTX-3 levels between septic and normal newborns. Very limited information is available in the literature concerning the normal serum PTX-3 level in newborns. Our review of the literature elicited no information for recommended cut-off values for PTX-3 in sepsis. A cut-off value of $3.2 \mathrm{ng} / \mathrm{mL}$ for PTX-3 in our own patient study resulted in a sensitivity for sepsis of $81 \%$ and a specificity of $69 \%$. This value of $3.2 \mathrm{ng} / \mathrm{ml}$ elicited an NPV and PPV for PTX-3 in sepsis of $78.4 \%$ and $72.7 \%$, respectively. We think that the value we recommend for PTX-3 can be used in future studies.

\section{Study Limitations}

The small number of patients in our study is an important limitation of the study. However, our study, which reveals important results for PTX-3, which can be an important marker in the diagnosis of neonatal sepsis, is important.

\section{Conclusion}

The data elicited from our study shows that PTX-3 can be used as a valuable marker in the differential diagnosis of neonatal sepsis. Determination of normal levels in newborns with values obtained in serial measurements in more comprehensive and multi-center studies and greater experience in this area are now needed.

\section{Ethics}

Ethics Committee Approval: This study was performed following approval from the University of Health Sciences Turkey, Istanbul Haseki Training and Research Hospital Ethical Committee (no: 271, approval date: 16.12.2015).

Informed Consent: Written consent to participate was obtained from the parents of all the babies enrolled before the study commenced.

\section{Authorship Contributions}

Concept: T.A., M.E., D.O., Design: D.O., A.U., Data Collection and/or Processing: T.A., E.A., Analysis and/or Interpretation: M.E., K.S., Literature Research: T.A., K.S., H.N.D., Writing: T.A., D.O., K.S.

Conflict of Interest: No conflict of interest was declared by the authors.

Financial Disclosure: The authors declared that this study received no financial support.

\section{References}

1. Dağoğlu T, Ovalı F, Samancı N. Neonatoloji: Yenidoğanın Muayenesi. 1.baskı. İstanbul: Nobel Tıp Kitabevleri Ltd Şti; 2000:81-8.

2. Stoll BJ, Hansen NI, Sánchez PJ, Faix RG, Poindexter BB, Van Meurs KP, et al. National Institute of Child Health and Human Development Neonatal Research Network. Early onset neonatal sepsis: the burden of group B streptococcal and E. coli disease continues. Pediatrics 2011;127:817-26. 
3 Odabaşı iO, Bülbül A. Neonatal sepsis. Sisli Etfal Hastan Tip Bul 2020;54:142-58.

4. Ng PC, Lam HS. Diagnostic markers for neonatal sepsis. Curr Opin Pediatr 2006;18:125-31.

5. Jaillon S, Bonavita E, Gentile S, et al. The long pentraxin PTX3 as a key component of humoral innate immunity and a candidate diagnostic for inflammatory diseases. Int Arch Allergy Immunol 2014;165:165-78.

6. Töllner U. Early diagnosis of septicemia in the newborn. Eur J Pediatr 1982;138:331-7.

7. Köksal N, Harmanci R, Çetinkaya M, Hacimustafaoglu M. Role of procalcitonin and CRP in diagnosis and follow-up of neonatal sepsis. Turk J Pediatr 2007;49:21-9.

8. Gürsu HA, Vitrinel A, Cömert $S$, et al. Neonatal Sepsisli Olgularımızın Prospektif Değerlendirilmesi. Med J Bakirkoy 2007;3:89-93.

9. Katar S, Devecioğlu C. Dicle Üniversitesi Yenidoğan Bakım Ünitesi'nde izlenen çok düşük doğum ağırlıklı bebeklerin değerlendirilmesi. Dicle Tıp Dergisi 2006;33:248-51.

10. Akin MA, Gunes T, Coban D, Ozgun MT, Akgun H, Kurtoglu $\mathrm{S}$. Pentraxin 3 concentrations of the mothers with preterm premature rupture of membranes and their neonates, and early neonatal outcome. J Matern Fetal Neonatal Med 2015;28:1170-5.

11. Edwards MS. Part 2: Postnatal bacterial infections. Fanaroff and Martin's neonatal-perinatal medicine: Diseases of the fetus and newborn. 9th ed. St Louis; 2011. p. 793-829.

12. Bulut MO, Bulut IK, Büyükkayhan $D$, et al. Neonatal sepsisli olguların retrospektif olarak değerlendirilmesi. Cumhuriyet Üniversitesi Tıp Fakültesi Dergisi 2005;27:63-8.

13. Satar M, Engin Arısoy A, Çelik iH. Turkish Neonatal Society guideline on neonatal infections - diagnosis and treatment. Turk Pediatri Ars 2018;53(Supll 1):88-100.

14. Zaidi AK, Thaver D, Ali SA, Khan TA. Pathogens associated with sepsis in newborns and young infants in developing countries. Pediatr Infect Dis J 2009;28(Suppl 1):10-8.

15. Perk Y. Yenidoğan Sepsisinde Antibiyotik Direncinin altı (2002-2007) yıllık Cerrahpaşa tıp faültesi deneyimi. istanbul üniversitesi Cerrahpaşa tıp faküktesi çocuk sağlığı ve Hastalıkları Anabilim Dalı Uzmanlık (Tezi). İstanbul; 2010.

16. Kordek A, Łoniewska B, Podraza W, Nikodemski T, Rudnicki J. Usefulness of estimation of blood procalcitonin concentration versus C-reactive protein concentration and white blood cell count for therapeutic monitoring of sepsis in neonates. Postepy Hig Med Dosw (Online) 2014;68:1516-23.

17. Aygün C, Oran O, Portakal O. Yenidoğanlarda Prokalsitonin düzeyleri ve sepsis tanısındaki yeri. Çocuk Sağlığı ve Hastalıkları Dergisi 2003;46:83-9.
18. Ovalı F. Yenidoğan enfeksiyonları. 1.baskı. İstanbul: İstanbul Medikal Yayınclık; 2006:107-60.

19. Ng PC. Diagnostic markers of infection in neonates. Arch Dis Child Neonatal Ed 2004;89:229-35.

20. Berger C, Uehlinger J, Ghelfi D, Blau N, Fanconi S. Comparison of C-reactive protein and white blood cell count with differential in neonates at risk for septicaemia. Eur J Pediatr 1995;154:138-44.

21. Barman M, Das B. A Study of Validity of Haematological Parameters in the Diagnosis of Neonatal Sepsis. Indian J Appl Res 2016;6.532-5.

22. Shyamala K, Subbalakshmi N, Raghuveera K. Role of platelet count and CRP level in Gram negative versus Gram positive bacterial sepsis in low birth weight neonates. Journal of Chinese Clinical Medicine 2010;5:474-9.

23. Benitz WE. Adjunct laboratory tests in the diagnosis of earlyonset neonatal sepsis. Clin Perinatol 2010;37:421-38.

24. Pizzini C, Mussap M, Plebani M, Fanos V. C-reactive protein and serum amyloid A protein in neonatal infections. Scand J Infect Dis 2000;32:229-35.

25. Agrawal A, Singh PP, Bottazzi B, Garlanda C, Mantovani A. Pattern recognition by pentraxins. Target Pattern Recognition in Innate Immunity: Springer; 2009. p. 98-116.

26. Lannergård A, Rosenström F, Normann E, Larsson A. Serum pentraxin 3 concentrations in neonates. Ups J Med Sci 2014;119:62-4.

27. Ge W, Wang HL, Sun RP. Pentraxin 3 as a novel early biomarker for the prediction of Henoch-Schönlein purpura nephritis in children. Eur J Pediatr 2014;173:213-8.

28. Ketter PM, Guentzel MN, Schaffer B, et al. Severe Acinetobacter baumannii sepsis is associated with elevation of pentraxin 3. Infect Immun 2014;82:3910-8.

29. Sciacca P, Betta P, Mattia C, et al. Pentraxin-3 in late-preterm newborns with hypoxic respiratory failure. Front Biosci (Elite Ed). 2009;2:805-9.

30. Polentarutti N, Bottazzi B, Di Santo E, et al. Inducible expression of the long pentraxin PTX3 in the central nervous system. J Neuroimmunol 2000;106:87-94.

31. Duman L, Cesur Ö, Kumbul Doğuç D, Çelik S, Karaibrahimoğlu A, Savaş MÇ. Diagnostic value of serum pentraxin 3 level in children with acute appendicitis. Ulus Travma Acil Cerrahi Derg 2020;26:699-704.

32. Brunetta E, Folci M, Bottazzi B, et al. Macrophage expression and prognostic significance of the long pentraxin PTX3 in COVID-19. Nat Immunol 2021;22:19-24.

33. Protti A, Meessen J, Bottazzi B, et al. Circulating pentraxin 3 in severe COVID-19 or other pulmonary sepsis. Eur J Clin Invest 2021;51:e13530. 